\title{
Focus on known active faults
}

To the Editor - A recent Commentary ${ }^{1}$ in Nature Geoscience argues that the highest priority in earthquake science and risk evaluation is to identify the myriad hidden faults in the continental interiors. Few could disagree that the development of methods that expose unknown killer faults is important science, but is mapping the seismic hazard throughout the ten million square kilometres of the Alpine-Himalayan belt the highest scientific priority? I argue that scientific priority should instead lie with identifying regions of the highest hazard where we have, or can collect, data on known active faults, and then we must work with non-scientists to make these regions more resilient.

For nearly 50 years we have known the location and basic properties of faults both at plate boundaries and, to a lesser extent, in the continental interiors, which are responsible for many devastating earthquakes. However, this basic, uncontested and widely accessible knowledge has had remarkably little effect on resilience in the developing world and has failed to persuade all but the most

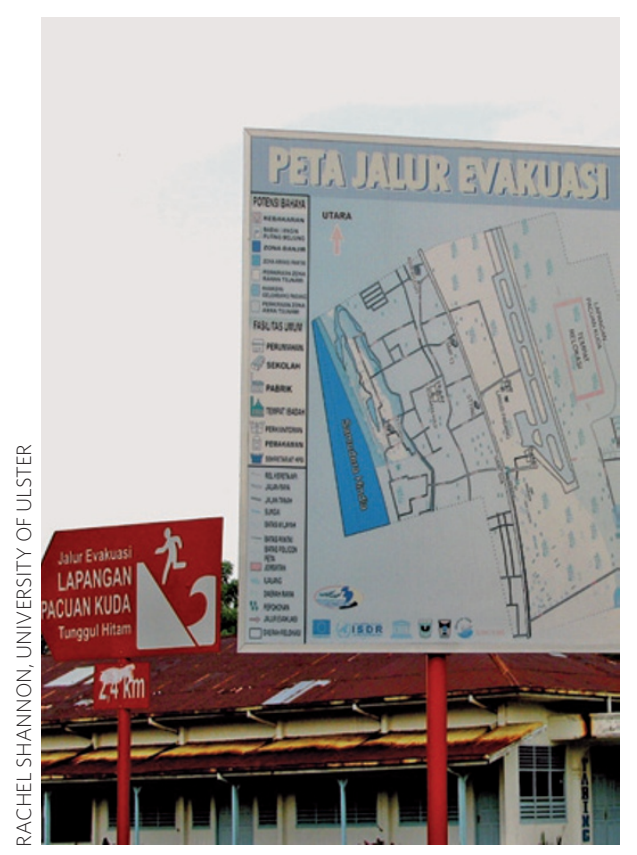

Figure 1 | Tsunami evacuation signs in Padang, Sumatra. A decade of research has identified Padang as a global hotspot for earthquake and tsunami hazard. An international effort is working to prepare the population there. affluent countries to invest appropriately in earthquake preparedness. The SumatraAndaman and Haiti earthquakes killed hundreds of thousands in places where the earthquake and tsunami risks were broadly understood.

Thankfully though, even in the developing world there are examples of success. The city of Padang in West Sumatra, Indonesia, has a population of 850,000 and sits adjacent to one of the world's highest earthquake and tsunami threats ${ }^{2}$. The city is the focus of an international effort to increase resilience to seismic hazard by planning for the next Mentawai earthquake, when a tsunami is likely to flood the city ${ }^{3}$. Education and evacuation drills based on tsunami-inundation modelling and the planned construction of vertical evacuation structures and bridges are steadily reducing vulnerability (Fig. 1). The case of Padang is an example of resilience building on a budget, based on a decade of multidisciplinary geoscience research that has helped to elevate the public awareness of threat beyond ignoring. And the principles applied here are potentially applicable to many mapped faults worldwide.

Of course, the work of science and preparedness in Padang is not complete and communities there are still more vulnerable than they need be. The September 2009 Padang earthquake ${ }^{4}$ exposed serious weaknesses in the city's building stock ${ }^{5}$, and preparedness that does not improve buildings is fundamentally incomplete. Additionally, analysis of the 2007 Bengkulu earthquake ${ }^{6}$ in southwest Sumatra and of the 2010 Chile earthquake $e^{7}$ shows that current models of earthquake recurrence fail to forecast the amount and location of slip. This is not a peripheral issue because the run up of the tsunami along the threatened coast will strongly depend on the distribution of slip during the expected Mentawai earthquake ${ }^{8}$. However, irrespective of these shortcomings, the central message of imminent danger in Padang is clear, concise and effective.

Earthquakes on unmapped faults will kill tens of thousands in the coming decades and the search for these faults is important; the Iranian government, for example, would do well to heed the warnings concerning the recently discovered fault in the centre of Tehran 9 . But nearly half a century of experience with known active faults suggests that their identification alone will not be nearly enough. Scientists will still need to identify and characterize the most hazardous segments of any newly discovered faults and then prioritize them for action along with currently known seismic-hazard hotspots.

We must continue to develop geodetic, geological, geomorphological and seismological methods for monitoring the build up of stress on faults and for reconstructing slip during recent, historical and ancient earthquakes. We must incorporate the resulting data into models of long-term stress accumulation and further develop statistical methods so that the uncertainties in our observations can be included in forecasting schemes based on properly bounded assessments of the state of stress on these faults. In turn, the forecasting schemes need to be tested using sophisticated, physics-based models of multiple earthquake cycles $^{10}$. And we should continue to work with social scientists, non-governmental organisations and insurance companies, as well as local scientists, geological surveys and governments. In this way, we can ensure that the scientific messages are tailored to increasing resilience in a way that is appropriate to the social, cultural and economic context of the target communities and that resilience building is adequately resourced both financially and scientifically.

We may never predict earthquakes. But surely we should steadfastly aim to forecast the locations of a large fraction of the devastating events that will occur on known faults in the next decade and mobilize all the allies we can to help prepare for them.

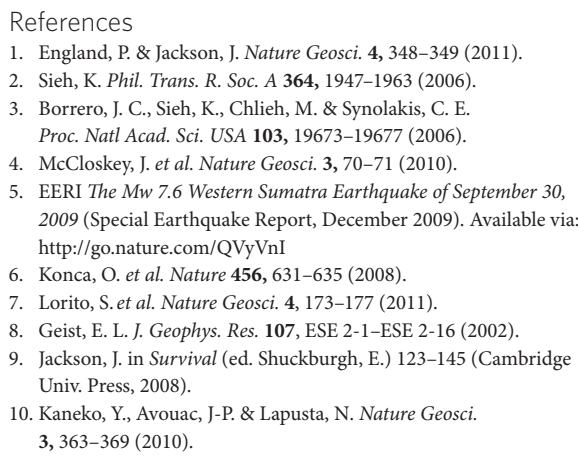

\section{John McCloskey}

Environmental Sciences Research Institute, University of Ulster, Coleraine, County Derry BT521SA, Northern Ireland.

e-mail: j.mccloskey@ulster.ac.uk 